This item was submitted to Loughborough's Research Repository by the author.

Items in Figshare are protected by copyright, with all rights reserved, unless otherwise indicated.

\title{
Forecasting infrastructure resilience to climate change
}

\section{PLEASE CITE THE PUBLISHED VERSION}

http://www.icevirtuallibrary.com/content/serial/tran

\section{PUBLISHER}

(C) ICE Publishing

\section{VERSION}

VoR (Version of Record)

\section{PUBLISHER STATEMENT}

This work is made available according to the conditions of the Creative Commons Attribution-NonCommercialNoDerivatives 4.0 International (CC BY-NC-ND 4.0) licence. Full details of this licence are available at: https://creativecommons.org/licenses/by-nc-nd/4.0/

\section{LICENCE}

CC BY-NC-ND 4.0

\section{REPOSITORY RECORD}

Dijkstra, Tom, Neil Dixon, Chris Crosby, Matthew Frost, David Gunn, Paul Fleming, and Joanna H. Wilks. 2015. "Forecasting Infrastructure Resilience to Climate Change". Loughborough University. https://hdl.handle.net/2134/17269. 
Transport

Volume 167 Issue TR5

Forecasting infrastructure resilience to climate change

Dijkstra, Dixon, Crosby et al.
Proceedings of the Institution of Civil Engineers

Transport 167 October 2014 Issue TR5

Pages 269-280 http://dx.doi.org/10.1680/tran.13.00089

Paper 1300089

Received 26/11/2013

Accepted 05/07/2014

Keywords: research \& development/sustainability/transport management

\section{Forecasting infrastructure resilience to climate change}

1 Tom Dijkstra PhD, FGS

Engineering Geologist/Geomorphologist, British Geological Survey, Environment Science Centre, Nottingham, UK

2. Neil Dixon BSC, PhD, FGS

Professor of Geotechnical Engineering, School of Civil and Building Engineering, Loughborough University, Loughborough, UK

3 Chris Crosby BSc(Hons), PGCE, PhD

Research Associate, School of Civil and Building Engineering, Loughborough University, Loughborough, UK

4 Matthew Frost BEng(Hons), DIS, PhD, PgCHE, MPWI Lecturer in Geotechnical Engineering, School of Civil and Building Engineering, Loughborough University, Loughborough, UK
5 David Gunn MSc, PhD

Team Leader Geotechnical Properties and Processes, British Geological Survey, Environment Science Centre, Nottingham, UK

6 Paul Fleming BEng, PhD, MIHT Senior Lecturer in Geotechnics, School of Civil and Building Engineering, Loughborough University, Loughborough, UK

7 Joanna Wilks MEarthSci(Hons), MSc, FGS Researcher, School of Civil and Building Engineering, Loughborough University, Loughborough, UK
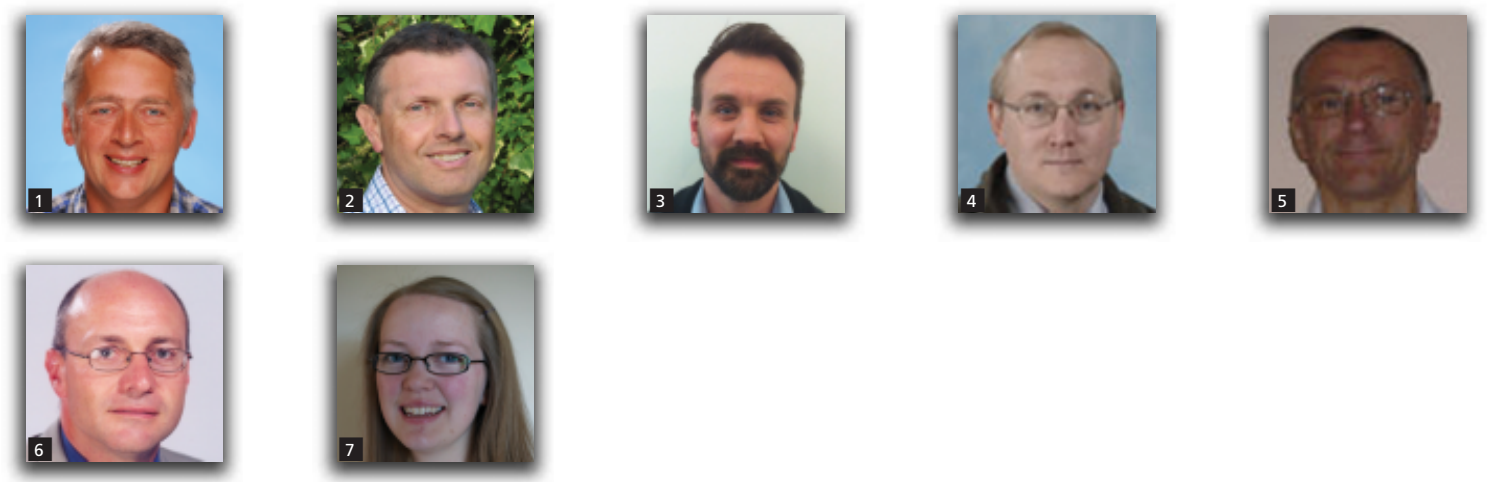

Resilience of the UK transport infrastructure network can be expressed as the imbalance between the physical condition of the network and the transport demands the network experiences. Forecasting changes of resilience in the long term (e.g. the 2050s) requires a structured, multi-disciplinary approach. The Engineering and Physical Sciences Research Council funded Futurenet project developed a model architecture to formalise such an approach and this paper addresses one component: the assessment of the influence of physical processes on asset condition. This requires the development of new, integrated physical-based models that respond to detailed inputs of forecast weather events (e.g. UK Climate Projections 2009). The results are plotted onto the infrastructure network for visualisation. Subsequent combination with user demand will then enable determination of network resilience at a range of spatial scales. The project has highlighted the need for better datasets, more sophisticated physical-based models and further analyses of complex feedbacks and interactions between physical processes and also with user behaviour.

\section{Introduction}

The potential consequences of climate change on UK society and its transport infrastructure are subject to much debate (e.g. Cabinet Office, 2011; Chapman, 2007; CILT UK, 2011; ICE, 2010; Jaroszweski et al., 2010; Thornton et al., 2010; URS, 2010). In support of this debate, the Engineering and Physical Sciences Research Council (EPSRC) provided funding for the establishment of the Futurenet project as part of its portfolio of research-led projects within the Adaptation and Resilience to Climate Change (ARCC) programme (www.ukcip-arcc.org.uk). Futurenet was tasked to determine a model architecture for the quantification of UK transport infrastructure network resilience in the 2050 s at a range of spatial scales. The project approached this problem from a user perspective, expressing resilience as the imbalance between the physical condition of segments of the network and the transport demand these segments will experience in the 2050s. The Futurenet project comprised a multi-partner, multi-disciplinary team that addressed a range of integrated investigations, including user behaviour surveys (Ryley and Chapman, 2012), projections of future travel demand (Berkhout et al., 2002; Goulden and Dingwall, 2012), the influences of weather on travel behaviour (Bouch et al., 2011, 2012) and the assessment of the effects of physical processes on asset condition as addressed in this paper.

It is widely recognised that climate change (Table 1) presents very 


\begin{tabular}{llc}
\hline 2050s (2040-2069) & Description & $\begin{array}{c}\text { Projected change of } \\
\text { baseline values } \\
1961-1990\end{array}$ \\
\hline Precipitation & Mean winter & $-10 \%$ to $+30 \%$ \\
Temperature & Mean summer & $-20 \%$ to no change \\
& Mean winter & $+1.0^{\circ} \mathrm{C}$ to $+3 \cdot 0^{\circ} \mathrm{C}$ \\
& Mean summer & $+1.0^{\circ} \mathrm{C}$ to $+3 \cdot 0^{\circ} \mathrm{C}$ \\
& Warmest day, summer & $+0.0^{\circ} \mathrm{C}$ to $+4.0^{\circ} \mathrm{C}$
\end{tabular}

Table 1. Summary data of forecasted change in temperature and precipitation compared to the 1961-1990 baseline for the 30-year static output centred on the 2050s based on the medium emissions scenario (Jenkins et al., 2009)

serious risks and that warming trends are stronger than earlier forecasts suggested (IPCC, 2007; Rowlands et al., 2012). It is clear that appropriate adaptation strategies for infrastructure need to be developed as the benefits of proactive intervention considerably outweigh the costs of remediation following failure (Glendinning et al., 2009; Jenkins et al., 2009; Jones et al., 2009; Murphy et al., 2009; RSSB, 2004, 2005; Stern, 2007). The UK has a strategic road transport network (motorways and trunk roads) covering more than $13000 \mathrm{~km}$ with some $400000 \mathrm{~km}$ of other public roads (Figure 1). The UK rail network spans some $15000 \mathrm{~km}$ (Defra, 2011; HM Treasury, 2011). Some two-thirds of the UK transport infrastructure network is supported by or adjacent to engineered slopes such as embankments and cuttings (Perry et al., 2001, 2003; Wilks et al., 2012). Existing infrastructure was constructed under a past climate and railway infrastructure in particular is affected by aged assets (120 years or more) and constructed to standards that are very different from present practice (Loveridge et al., 2010; O’Brien, 2007). Maintaining these assets is costly. For example, Network Rail invested some $£ 70$ million on preventative works to stabilise at-risk earthworks in 2007/2008 (RAIB, 2008). It is therefore cost-effective to develop tools to enable asset managers to prioritise better where sections of the network require investments to maintain resilience.

At present, most climate impact studies for the infrastructure sector are based on narrative development and empirical assessments (e.g. Koetse and Rietveld, 2009). Broad expert elicitation processes form very useful fora for capturing the detailed narratives that set out a comprehensive framework for addressing potential climate change impacts on key infrastructure assets in the UK (e.g. energy, transport, water) (URS, 2010). In a conceptual framework for strategic decision-making, these suites of narratives form very useful tools. However, it is now required to analyse changes in the condition of these assets in greater detail and to communicate more effectively the spatial and temporal distribution and forecasted severity of climate-dependent hazards, such as flooding, landsliding, swell/shrink and railway buckling. Futurenet therefore responds to the argument that physical process representation for the determination of the

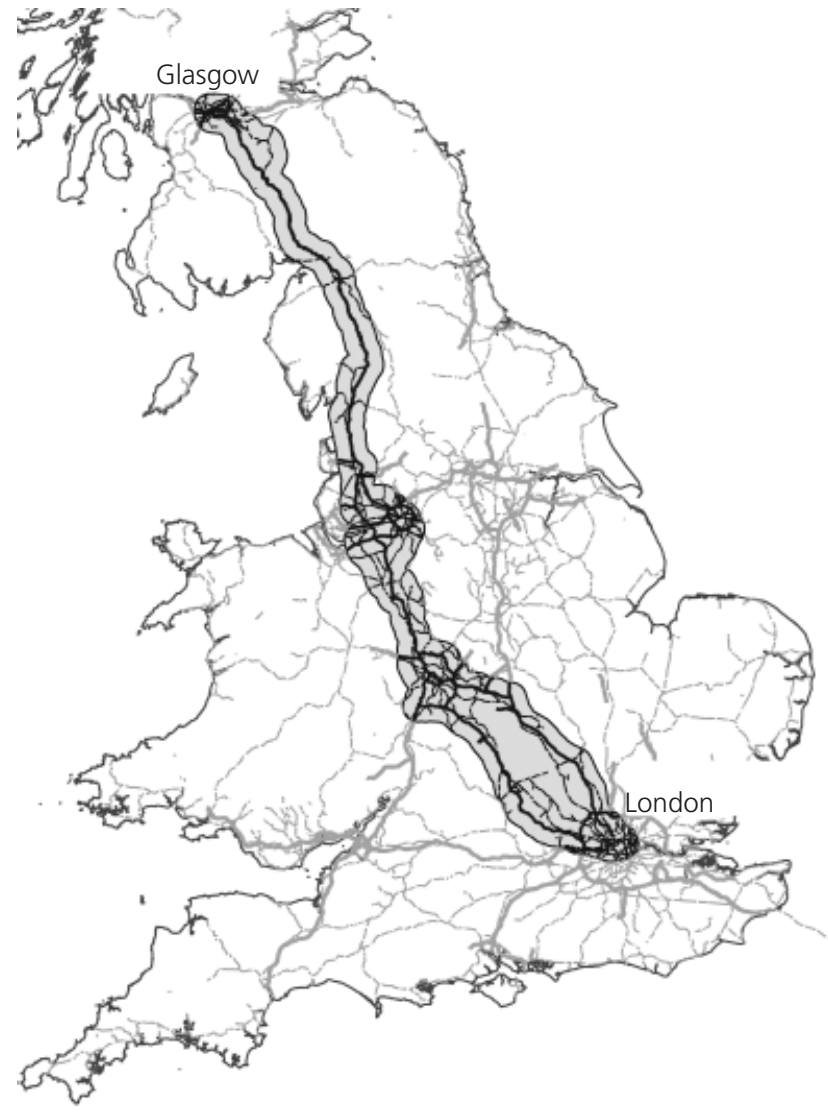

Figure 1. The major UK transport infrastructure network (road, rail, airports) and the Futurenet corridor; contains Ordnance Survey data (C) Crown Copyright and database rights 2013

infrastructure asset condition in a dynamic environment requires a shift in focus towards quantitative modelling (Dijkstra and Dixon, 2010). The Futurenet project is among the first to respond to a need to put long-term forecasting of infrastructure network resilience in a quantitative framework, where physical-based 
process models are driven by high-resolution weather data. This paper describes the Futurenet model architecture and presents the physical condition and capacity reduction approach. This is illustrated using example outputs from the model and leads to a discussion of how uncertainties could be reduced and model performance may be improved.

\section{The Futurenet architecture}

The development of the Futurenet model architecture was carried out with the following three sets of viewpoints in mind.

- Those of the policy maker, who needs to be able to make long-term strategic choices, for example those associated with prioritisation of long-term investments in infrastructure planning.

- Those of the infrastructure manager, who requires detailed assessments of local impacts on specific infrastructure for different weather events.

- Those of the traveller, who is interested in an improved understanding of, for example, the time taken to travel a particular route on a specific day, and the assessment of delays associated with a reduced resilience due to adverse weather conditions.

Communication of Futurenet outcomes thus requires different levels of detail (see Figure 2). At the site-specific highest resolution, process modelling takes place that can be used to provide information on the heterogeneity in the process-response system to site managers, planners and maintenance groups. Changes in condition of the asset are influenced by individual processes or interactions between multiple physical processes. Aggregation of information will enable the creation of outputs that are relevant to segments of the infrastructure corridor between nodes. Nodes are locations on the network where deviations from a particular route are possible. In the motorway environment this is dependent upon, for example, major junctions or breaks in the central reservation that emergency/maintenance services could potentially use to direct traffic onto another functioning carriageway. For rail, these nodes are locations where rolling stock can change tracks. It is argued that if something occurs anywhere between the nodes, the whole segment is affected and thus the weakest component determines the functioning of the segment. Further aggregation of information can involve averaging multi-segment stretches into strategic units that can be determined on a regional or even national basis (for example the M1 motorway unit through Leicestershire, or the rail and road corridor from London to Glasgow). The expression of changes in aggregated physical condition for these units, and combinations of road and rail routes, can provide important information to support strategic decision-making on a regional/ national scale.

\subsection{Conceptual framework}

The Futurenet model architecture is structured around a general framework that conceptualises the basic steps that are required to quantify the resilience of a portion of the infrastructure network that a user needs to engage with. This is discussed in some detail by Bouch et al. $(2011,2012)$ and is briefly addressed here for clarity using Figure 3 as a guide. A user intends to set out at a particular time on a journey along a particular route that comprises $N$ segments (a section between two nodes, or an aggregation of more detailed information). This constitutes a travel scenario for which all the variables are defined. The journey will take place some time in the future (e.g. 2050) and climate forecasts will need to be determined. Similarly, this user will travel in an environment where a certain population of other users will interact on the network (this is based on a snapshot of the future derived from futures-based user demand forecasts). The type of user under consideration will be subject to a series of thresholds that are user-specific. These could be split into

- serviceability limit states (SLSs) - delays that are inconvenient but where the destination can be reached within acceptable timeframes

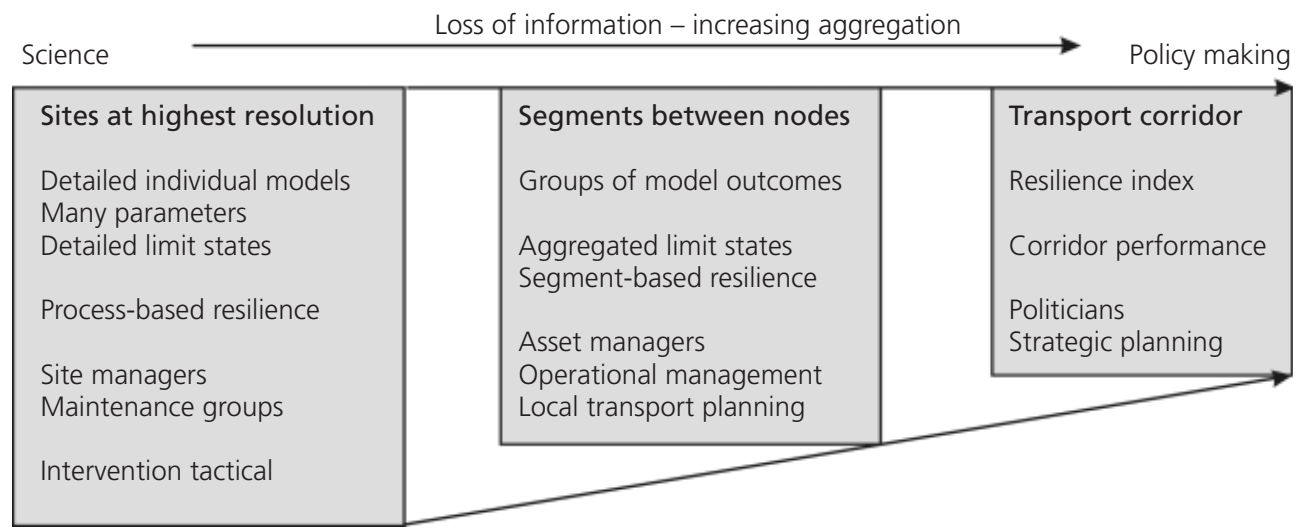

Figure 2. Communication framework for the Futurenet architecture. Model performance needs to satisfy the greatest possible detail. Through aggregation of information, different levels of communication can be derived that will be better suited to different user groups 


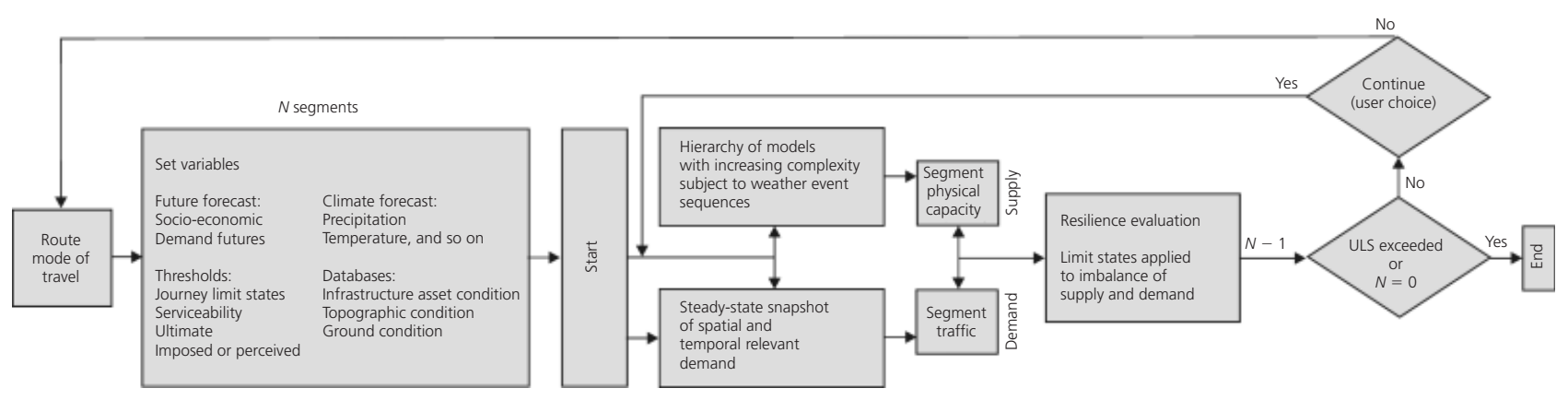

Figure 3. Outline of the process model for the Futurenet project. Physical process models are used to drive an understanding of segment capacity (the physical condition of the asset) and also provide inputs into the behaviour of users and thus indirectly also influence demand. ULS, ultimate limit state ultimate limit states (ULSs) - delays that result in the user either arriving too late or not at all, and hence the journey has failed.

These limit states could be imposed (e.g. through work-based performance needs) or perceived (e.g. one person's slight delay is another person's trigger to abort the journey).

The final components to complete the travel scenario comprise information on all the relevant segments derived from the transport corridor databases and include inputs on the infrastructure assets (including drainage, engineered interventions, carriageway properties), ground conditions (including geotechnical parameters, land use, geology, vegetation) and topographical conditions (including regional relevance, morphometry, elevation). Finally, an optimum duration for progression through each of the segments can be calculated. Once these conditions are set, the scenario can be followed through and the 'journey' can start by looking at the progression through each of the segments of the journey sequentially. The physical-based process models and the user behaviour models then interact to provide an expression of local resilience, which can be coupled with a degree to which flow through the segment is compromised. The physical-based models determine the capacity of the segment and the user behaviour models determine fluctuation in demand. This, in turn, enables evaluation of the difference between the optimum time projected at the onset of the journey and the time taken as returned by the calculated imbalance between capacity and demand. At the end of each segment there is an option for the user to test the progression of the journey by evaluating the difference between the optimum time required and the time returned by the model. This could result in progress to the next segment (if delay is below a critical threshold) or abandonment/ change of the journey, at which point a new scenario with difference segments can be arranged and a next cycle of analysis commences.

The Futurenet project considers that resilience represents the ability to provide and maintain an acceptable level of (environ- mental, economic and social) service in the face of challenges to normal operation (see also Rogers et al. (2012)). This resilience is driven by the imbalance between the physical condition, and hence capacity, and the demand for a particular unit (a location, a segment or an aggregation of segments) of the transport infrastructure network. Recovery from a loss of resilience can be the result of a fall in demand or a reduction in intensity of the adverse consequences of weather events that affect the physical capacity. Further limit states can be defined, relevant to this imbalance. For the narrative of this project, two SLSs (SLS1 and SLS2) and one ULS are used as conceptual examples to designate the zones in which the network functions. Below SLS1, the network functions without any problems. Between SLS1 and SLS2 it is functioning at acceptable levels. Between SLS2 and ULS the network becomes increasingly stressed and it finally fails on or above the ULS.

It should be noted that, in this project, demand or trip assignment for each segment is not specifically modelled by way of a traditional transport model (although this could be incorporated in the architecture in future). Instead, diurnal demand fluctuations (at hourly intervals) reflect forecasted demands in 2050 and these are linked to the modelled physical state for a segment of a route. ULS failure could be the result of closure of a segment due to a comprehensive loss of physical infrastructure (demand in this case is irrelevant). However, a complete loss of functionality of the transport segment can also occur when there is a moderate reduction in physical capacity at a time when there is a (projected) high demand. The same reduction in physical capacity at low demand will have a much smaller effect on serviceability. It is recognised that much more complex interactions between physical capacity and projected demand can be evaluated and modelled, but these fall outside the current scope of this research.

The concept of resilience can be illustrated in different ways. In Figure 4(a), capacity and demand are shown as a downscaled $24 \mathrm{~h}$ snapshot of a future year (e.g. the Futurenet target year 2050) with capacity reductions determined by physical process models responding to hourly weather event inputs and transport demand based on hourly fluctuations informed by narratives of 


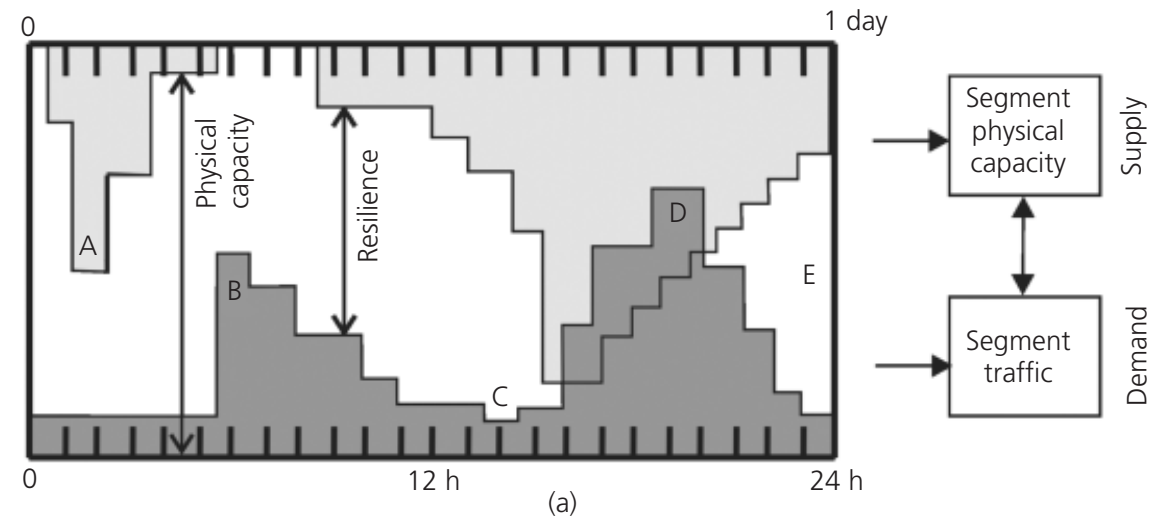

(a)

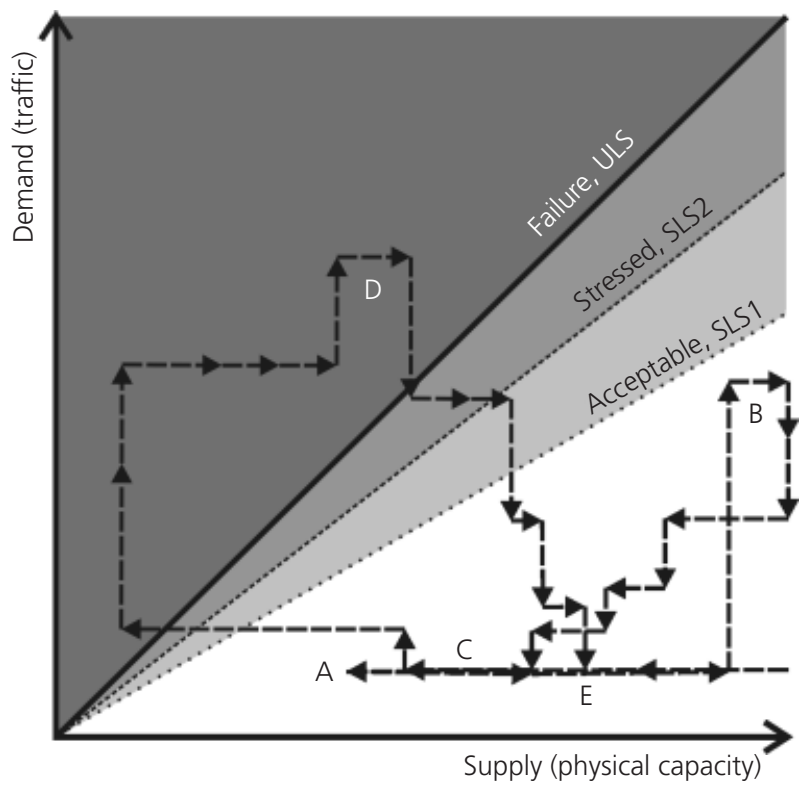

(b)

Figure 4. (a) The concept of resilience represented by 'white space' within an 'asset capacity-time' box representing a small transport infrastructure unit. Reduction of physical capacity is indicated by the dimensions of the light-grey shaded bars dropping down from the top of the box. Traffic (demand) over this $24 \mathrm{~h}$ period is indicated by the dark-grey bars rising up from the base of the box. (b) Capacity-demand diagram enabling analysis of hourly vectors against pre-determined limit states. Both diagrams are based on the same fluctuations of supply and demand. Letters $A$ to $E$ are used to facilitate comparison socio-economic futures. The asset is represented by the box, the height of which reflects its full potential. This potential can be compromised by a reduction in physical capacity or by fluctuations in demand. The former is represented by the downward propagation of the shaded area and the latter by upward propagation. The white space in between provides an indication of resilience. Narrowing of the white space indicates loss of resilience and transgression of serviceability states. Overlapping light grey and dark grey bars indicate total failure, where the ULS is exceeded. This information was used to determine the relationship between physical capacity supply and traffic demand, illustrated in Figure 4(b). This allows representation of the $24 \mathrm{~h}$ pathway of resilience for a particular segment as a series of hourly vectors, illustrating the fluctuations of resilience and enabling delay assessments to be determined.

\subsection{Physical process identification}

The infrastructure network is a complex system with an in-built spatial and temporal heterogeneity that makes it very difficult to capture process fluctuations that can impact on overall network performance. It comprises anything from the natural environment adjacent to the transport infrastructure asset (e.g. rivers and slopes) to the engineered assets (e.g. earthworks, drainage, road surfaces, railway track, signalling, gantries, bridges and tunnels) that form an effective transport system. The physical assets are therefore multi-faceted in their own right, but are also placed in a corridor where the adjacent environment and impact potential is determined by the spatial relevance of individual physical processes, creating multiple boundaries ranging from the relatively confined swell/shrink behaviour of earthwork embankments to the broad, catchment-based assessments of the potential 
Transport

Volume 167 Issue TR5
Forecasting infrastructure resilience to

climate change

Dijkstra, Dixon, Crosby et al. consequences of fluvial flooding. This is illustrated in Figure 5, as follows.

1: A road positioned along the base of a slope can be affected by excess runoff/erosion, determined largely by upslope length and land use.

- 2: A road positioned on high ground/top of a slope is likely to be exposed to high winds (e.g. Quinn and Baker, 2010).

- 3 (cuttings) and 4 (embankments): Engineered structures with variable conditions dependent upon age and position in the landscape and geological materials in or on which these are constructed, affecting, for example, swell/shrink processes (Loveridge et al., 2010; O'Brien, 2007; Take and Bolton, 2004).

- 5: Position of infrastructure assets in a floodplain environment requires assessment of flood risk that needs analysis of whole-catchment dynamics (e.g. Christierson et al., 2012).

6: Slope stability assessment is still an area where local conditions determining time and place of failure are only possible to model in exceptional circumstances, although capabilities to fine-tune modelling of the propensity of failure are progressing.

7: Scour of support structures in dynamic landscapes such as

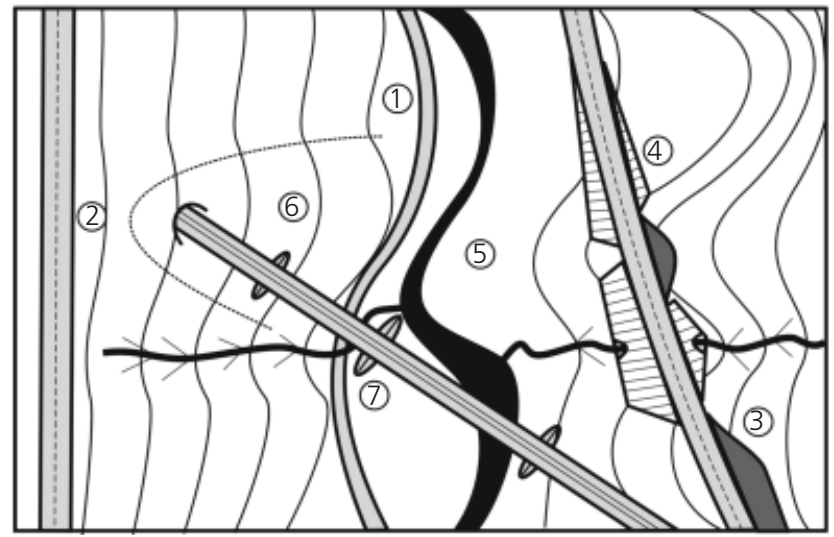

Figure 5. Conceptual diagram illustrating the complexities of infrastructure asset placement in the landscape river corridors requires further research and, most importantly, better asset condition information (Roca and Whitehouse, 2012).

\subsection{Multi-process model development and weather event sequences (WESQs)}

The hierarchy of models that determine the segment physical capacity shown in Figure 3 can be represented by a simplified cascade (Figure 6) that formally links the following.

- Probabilistic climate input components, including WESQs, involving characterisations of hourly inputs of precipitation and temperature using duration, intensity and quantity.

- Physical process manifestations, constrained by topographical, ground and asset conditions, and responding to WESQs. These include: precipitation affecting pluvial, fluvial and internal hydrology characterised by volume or depth, pressure and flow of water; or temperature affecting air temperature and materials temperature and characterised by intensity, flux and freeze/thaw boundary transgressions.

- Probabilistic outcomes, both in terms of process events and user consequences (as determined by the process environment including skid resistance, vision and ride quality). These events are subject to SLS and ULS providing a threshold constraint for resilience evaluation.

\subsubsection{Probabilistic climate inputs}

The UK Climate Projections 2009 (UKCP09) weather generator provides probabilistic outputs that make it difficult to evaluate these process interactions. At present there is insufficient knowledge available to be able to determine the synergies of process interactions on a probabilistic basis. It was therefore decided to extract a number of WESQs from the ensemble outputs of the weather generator using the high-emissions scenario outputs from UKCP09 centred on the 2050s. This ensemble output comprises 100 runs of a 30 -year period (i.e. 3000 sets of annual WESQs) (Jones et al., 2009), which provides a set of weather years against which the model performance of the Futurenet architecture could be developed. The WESQs form the main driver of a basic cascade that, through a series of logical steps, enables one to determine the influence of physical processes on capacity (the infrastructure asset condition in a specific place and time along

\begin{tabular}{|c|c|}
\hline \multicolumn{2}{|c|}{ Probabilistic inputs - climate } \\
\hline $\begin{array}{l}\text { Climate variables } \\
\text { Precipitation }\end{array}$ & $\begin{array}{l}\text { Weather event sequences } \\
\text { reflection probabilistic forecasts }\end{array}$ \\
\hline & $\begin{array}{l}\text { Including scenarios of future } \\
\text { weather reflecting variations }\end{array}$ \\
\hline Plus derived data & $\begin{array}{l}\text { in duration, intensity and } \\
\text { quantity }\end{array}$ \\
\hline
\end{tabular}

Figure 6. Physical process model cascade represents the links between probabilistic weather event sequence inputs and the process/user consequence outcomes. Within the process

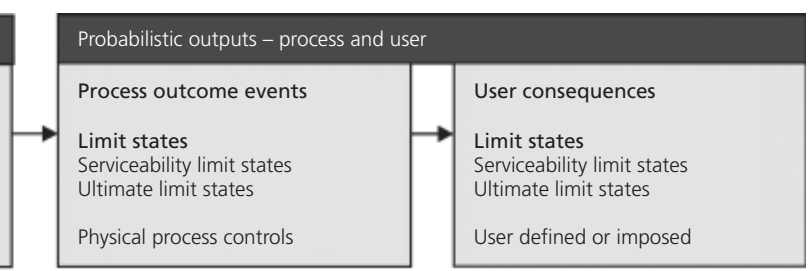

manifestation box, a complex hierarchy of different physical processes can be run either individually or in various combinations 
the network). Each WESQ is taken from the weather generator output and has a specific probability of occurrence that, in turn, affects the probability of the resultant outcome events. The detailed rationale underpinning this use of WESQs falls outside the remit of this paper.

\subsubsection{Physical process manifestations}

Physical process manifestations are constrained by a suite of conditioning parameters. The 'infrastructure condition' represents an additional layer of complexity and includes assessments of the relative position in the planning/operation and maintenance cycle of the physical asset. It could also incorporate algorithms to develop the infrastructure over time to cope with increased demand arising from economic/population growth in a fashion concomitant with the opportunities offered by scenarios such as those based on the foresight futures (see e.g. Curry et al. (2006)). The 'ground condition' incorporates quantifiable parameters characterising landforms, hydrology and material properties. The 'topographic condition' provides a mechanism to identify the intensity of processes such as the convergence of surface water flow, adjacent slope length and angle, and relative position of the infrastructure asset in the landscape. Both antecedent and current conditions determine the magnitude of a physical process response at a particular site and combined effects of simultaneous occurrences of different physical processes can only be analysed consistently if the same sets of WESQs are used for all physical processes.

Important factors to be considered when interpreting these physical process manifestations include the following.

- Cascade failures - these occur where exceeding a threshold of one particular process triggers a threshold of another process (e.g. scour leading to a landslide, resulting in road closure).

- Regional interdependencies - where occurrences in one region determine the conditions in another, including fluvial flooding at key transport locations and other disperse effects of local hazards.

- Synergies - where the effects of combined occurrences of processes are greater than the sum of these individually, including flooding combined with landslides.

- Magnitude and frequencies, or system response versus system recovery. The timing of events needs to be considered in the context of the recovery of the system and if the frequency of occurrence of critical (weather) events is greater than recovery of the asset condition this may result in prolonged system instability (Dijkstra and Dixon, 2010).

\subsubsection{Process outcomes and user consequences}

The physical process outcomes are linked to the consequences for the user. The methodology initially assumes a single user (traveller), and follow-on work is required to cover the situation of multiple users. A user may be considered a 'unit' such as a car or truck or a train. Interactions between multiple users are thus dependent on behaviour analyses, capacity constraints and demand forecasts (e.g. Hooper and Chapman, 2012).

\section{Physical condition and capacity reduction}

The physical-based modelling process was tested in an area centred on Garstang, Lancashire, in northwest England, located on the Futurenet London-Glasgow corridor (Figure 1). For the purpose of this test, the transport infrastructure corridor is represented by points plotted at equal $50 \mathrm{~m}$ distances along the route (Figure 7). This provides the current maximum resolution where a sequence of points between two nodes (where diversion from a route is possible) constitutes a segment and where multiple segments form a journey. In the raster geographic information system (GIS) approach used, access to the model and the data is through these point locations. This point-based information is then extended to a $75 \mathrm{~m}$ diameter buffer zone, which is populated with data and provides the maximum resolution for running the physical-based process models constructed on the basis of a one-dimensional tank model.

The main transport infrastructure comprises the M6 motorway, the busiest section of road in this area, and the west coast main line rail route, which is the busiest mixed-rail route in Europe. The main segment nodes on the M6 are at junction 32 (north Preston), junction 33 (Lancaster University) and junction 34 (Lancaster); for rail, these are at the stations at Preston and Lancaster (Figure 7). This location was selected because of the proximity of railway and motorway infrastructure so both could be analysed in similar settings. Land use is predominantly agriculture with small, scattered villages and dwellings. Additional considerations included contrasting topography, geology and assets at each site, and a history of physical process impacts on the resilience of infrastructure segments in this region (see Wilks et al., 2012).

The transport corridor is crossed by a number of rivers from east to west. These include the River Wyre, River Calder and River Brock and incorporate a large catchment of other tributaries, which drain towards the west from the Pennines into the Irish Sea. Ground condition includes a mixture of bedrock comprising millstone grit group rocks and Sherwood sandstone group rocks overlain by superficial surface deposits of alluvium and tills. Engineered slopes along the network are generally constructed in, or using, these local superficial and bedrock materials and are thus quite heterogeneous. The climate in the study area is temperate and experiences mean temperatures of approximately $6^{\circ} \mathrm{C}$ and mean annual precipitation rates of $850 \mathrm{~mm}$.

Spatial characteristics can be determined through identification of single points and areas, or by aggregating a number of points, where mean values can be calculated to determine a larger area representing a particular resilience. However, larger buffer zones are required for calculating effects on the process models when catchment characteristics are important, particularly when considering fluvial flooding and other regional hydrogeological influences. The GIS environment used provides ample flexibility to 
Forecasting infrastructure resilience to

climate change

Dijkstra, Dixon, Crosby et al.

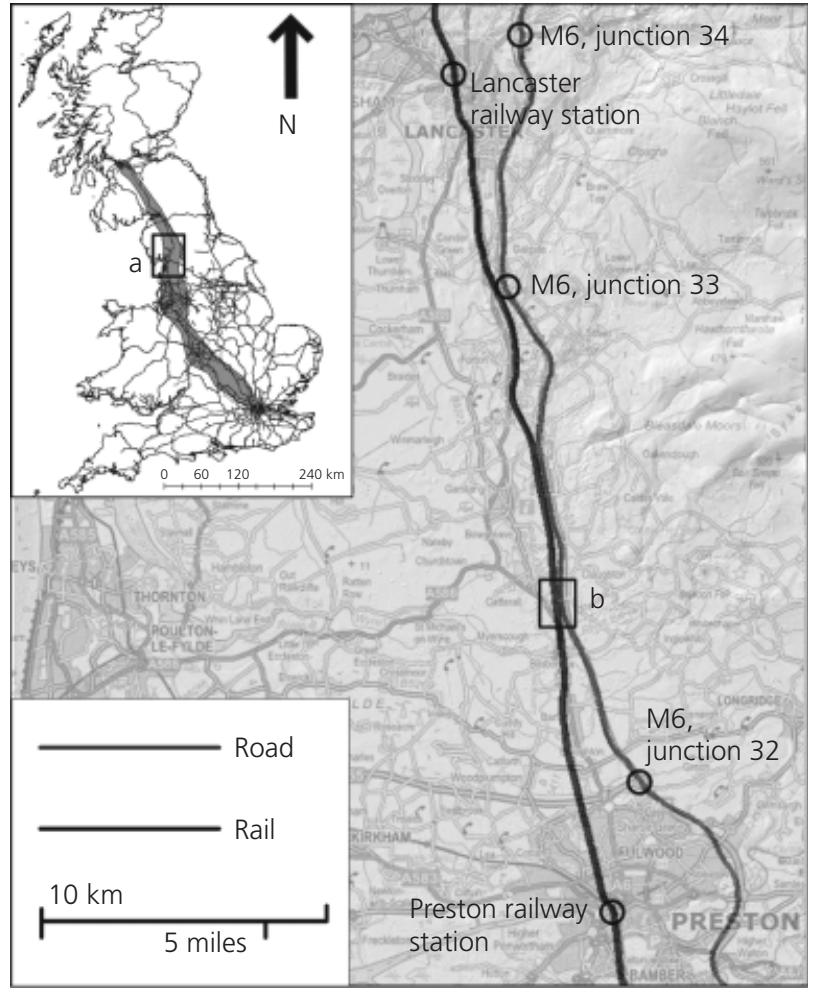

(a)

Figure 7. (a) Location of the study section between Preston and Lancaster in northwest England. (b) Map detail of the infrastructure corridor with information based on $50 \mathrm{~m}$ spacing

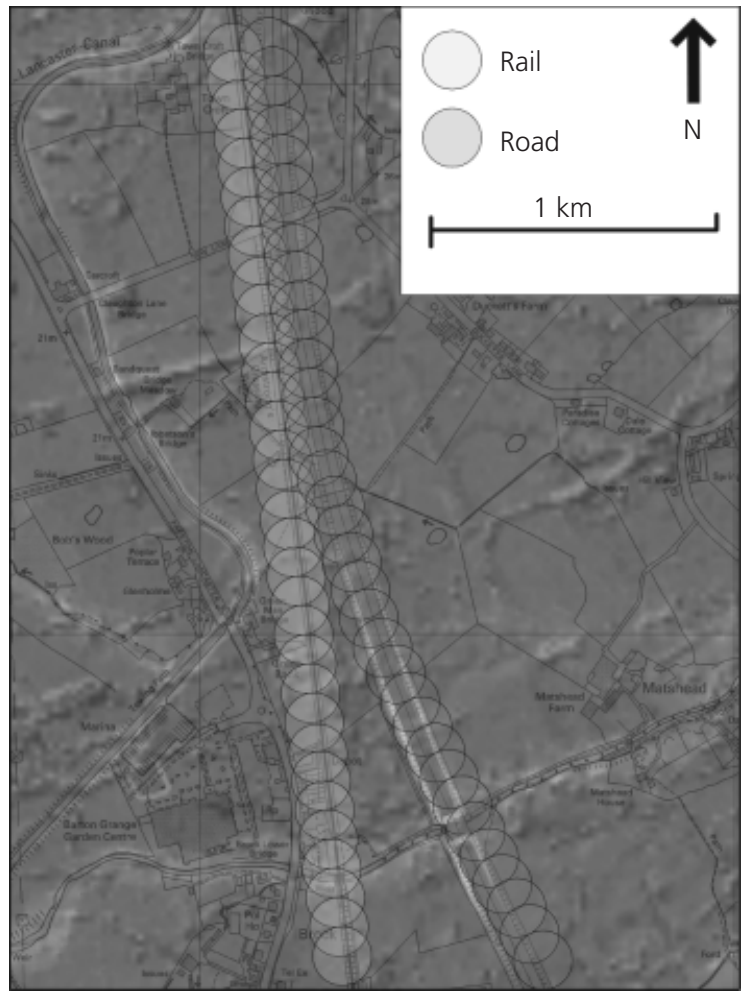

(b)

and 75 m buffer zones; contains Ordnance Survey data (C) Crown Copyright and database rights 2013; NEXTMap Britain elevation data from Intermap Technologies incorporate large buffer zones if the physical-based models require this.

A road user travelling in 2050 would need a network resilience assessment based on a snapshot of the time period during which the user is planning to travel. However, an infrastructure asset manager who is planning to forecast resilience in 2050 would likely need to run the model over a longer period of time in order to spot the times and conditions when network resilience dips below limit state thresholds for a particular WESQ and a specific location. This is illustrated in Figure 8. A WESQ (02/29) representative of the 2050 high-emissions scenario has been lifted from the ensemble forecast from UKCP09 to form the main input into a simple tank model (in Figure 8 only precipitation is shown, but temperature is also used) for this location - an embankment slope characterised by a fine-grained, till-derived engineered material covered by low vegetation including grass and brush. The results provide outputs to a suite of other physical-based process models, such as surface deformation associated with slope instability or shrink/swell and carriageway water film thickness. The hydrological responses of the slope are indicated by fluctuations in the soil storage volume and the position of the groundwater table. The outcomes of each physical process are then translated into an associated capacity reduction factor (crf) normalised between values of 1 (no effect) and 0 (complete loss of asset function). These crf values can be used individually, or combined, to provide an indication of the changes in physical asset condition. In Figure 8, the physical condition of the slope is illustrated by three crfs - overland flow, slope deformation and shrink/swell. In addition, a weighted combined crf is shown that provides an insight into the overall reduction of physical condition of the asset at this location.

Individual location outcomes can be combined to enable the generation of a temporal snapshot of the transport infrastructure asset condition for a larger area, as shown in Figure 9. This can be used to illustrate how the network performs at the highest resolution and when these are aggregated into segments for three process examples (overland flow, drainage and shrink/swell potential). The impact of these physical processes can result in a low intensity, as illustrated in the overland flow diagram. Aggregation of the point information into segment performance results in a reduced condition, but still at, or around, serviceability limits. However, when one point in a segment performs really poorly, as is the case for the drainage example, the whole segment will be affected. This ultimately also affects how all 

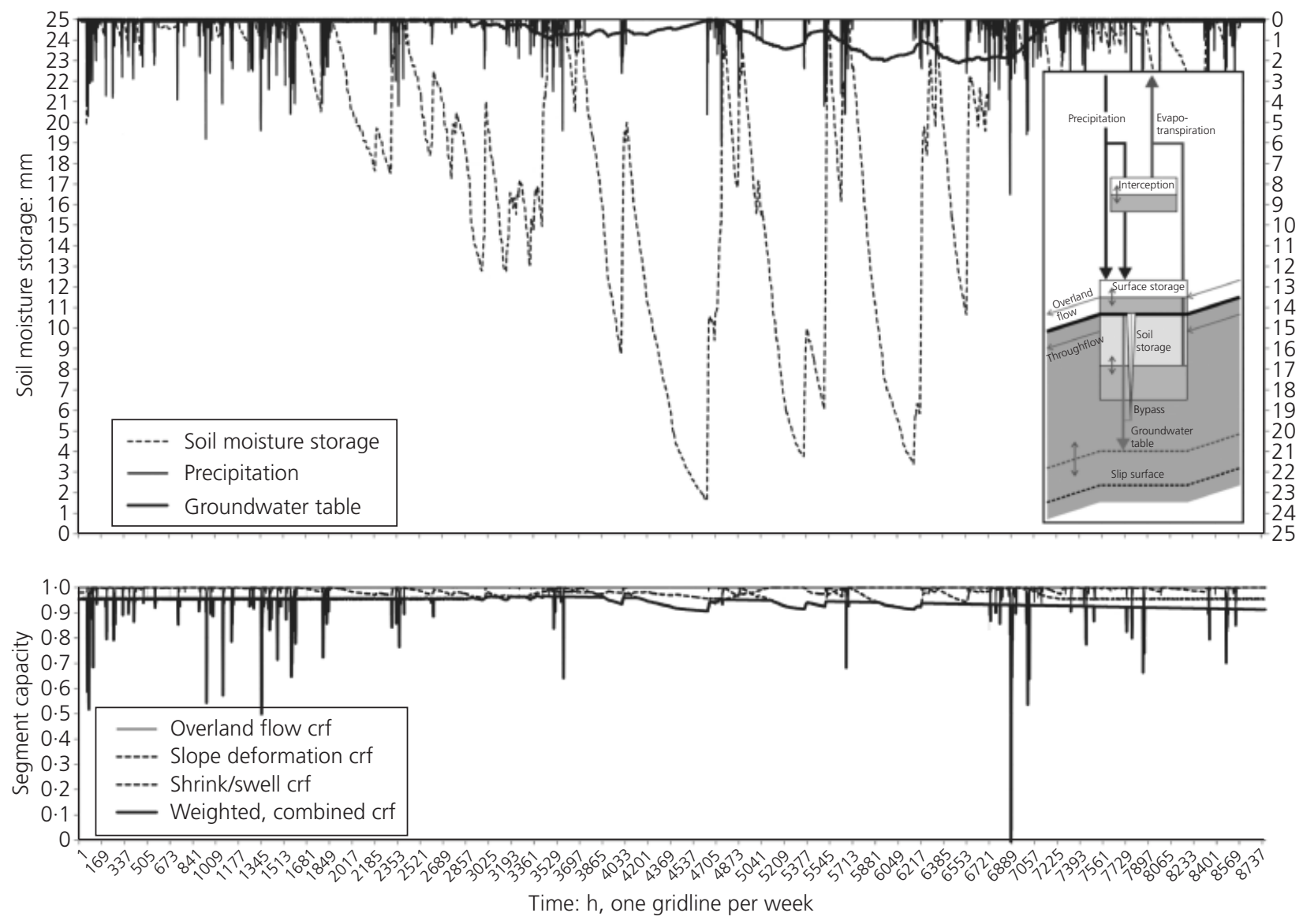

Figure 8. Example of the model performance for one location and one asset type along the transport corridor near Garstang; crf, capacity reduction factor
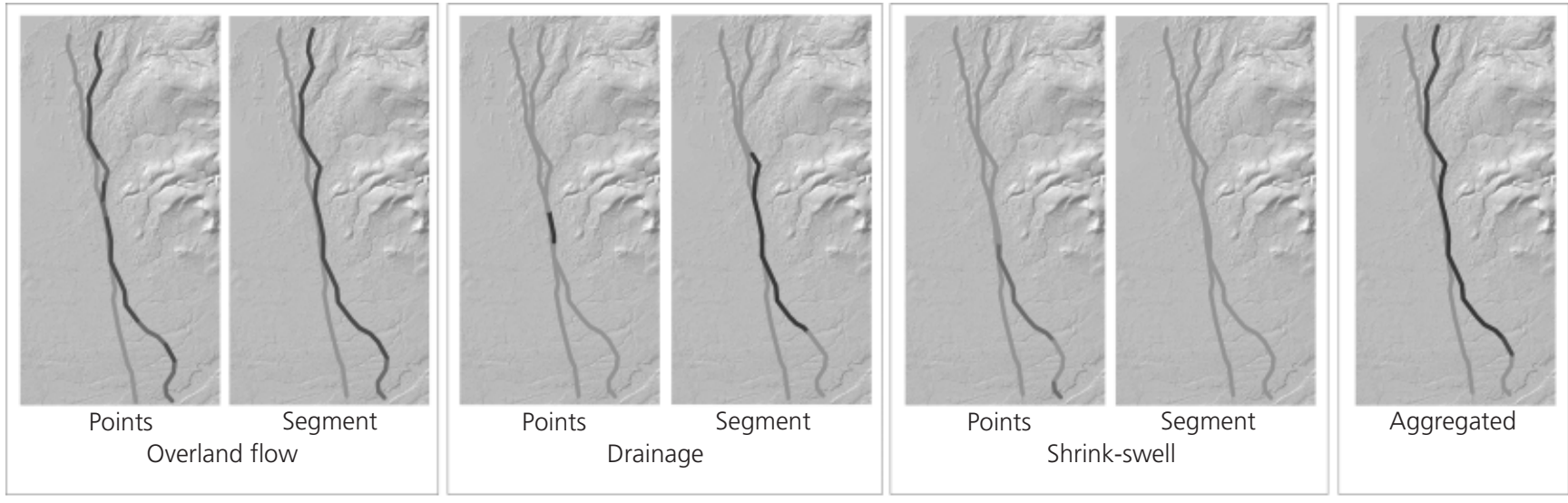

\section{$\bullet \bullet \bullet \bullet \bullet \bullet$}

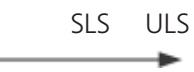

Figure 9. Impact of individual physical process models on the condition of infrastructure assets at the highest resolution for the Futurenet study section shown in Figure 7; contains Ordnance
Survey data (C) Crown Copyright and database rights 2013; NEXTMap Britain elevation data from Intermap Technologies 
individual capacity reductions are aggregated (these indicators do not reflect the current asset condition and are shown only for illustrative purposes).

\section{Reducing uncertainties and improving model performance}

It is now possible to represent combinations of 'capacity' and 'demand' for any particular time by a point cloud of coordinates $\left(v_{1}, v_{2}\right)$ obtained from multiple model runs. This concept is illustrated in Figure 10 where point clouds can be represented by ellipses that can be skewed in any direction and provide an insight into the degree of uncertainty associated with both variables (capacity and demand). The ellipses illustrate snapshots at 20year intervals and the dimensions of these ellipses aim to represent characteristic fluctuations in physical capacity and demand. The height is determined by demand fluctuations and the width by uncertainties of the physical capacity of the network. It is possible to hindcast using historical conditions (asset and user) to understand better the physical-based model performance, and also to forecast to 2050, based on current process understanding. Based on present forecasting capabilities, the capacity-demand ellipse for 2050a will inevitably be very large (representing great uncertainty in the forecasts). However, as time progresses, this capability will continue to improve and, combined with proactive network resilience management, will likely result in a much better defined near-future forecast (as illustrated by the 2020 ellipse with a narrow physical capacity shape). In turn, this should lead to a much improved long-term forecast, 2050b.

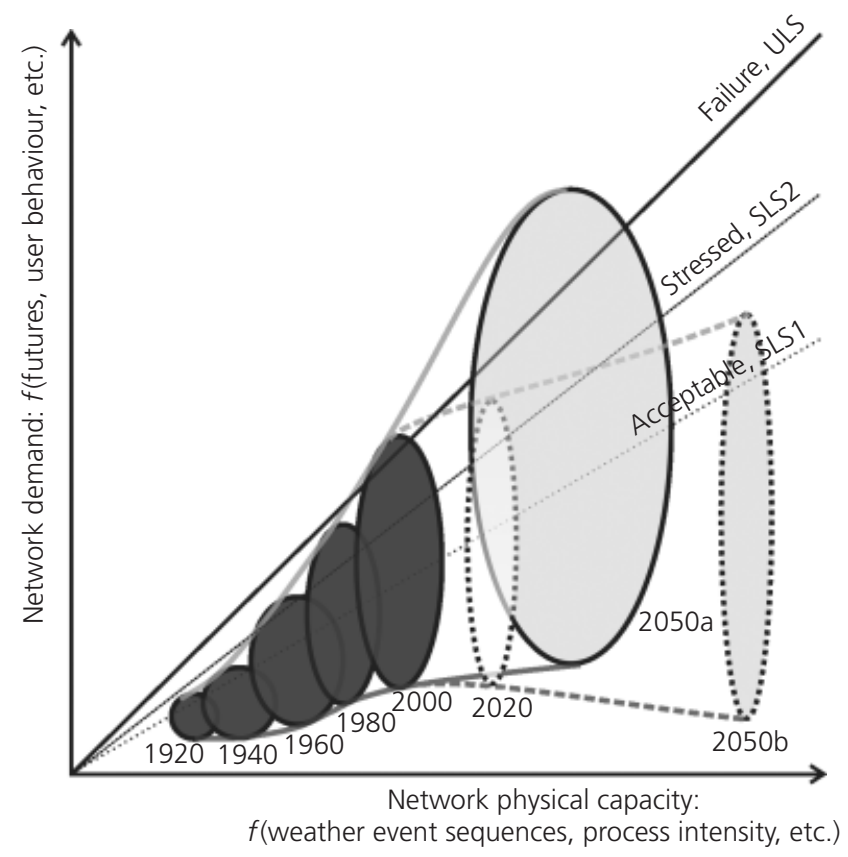

Figure 10. Historical development of the transport network driven by rises in network demand (a function of futures and user behaviour) and physical capacity (a function of WESQs and physical processes)
There is a need to continue to strive towards achieving a workable hierarchy of distributed conceptual models of acceptable complexities that are underpinned by a plausible physical basis and that return a reasonable correspondence with reality. As time progresses and the capability improves to model the physical processes in the natural and engineered landscape, new models can be inserted into the hierarchy, resulting in better performance and narrowing down of the uncertainties. However, this process requires significant investment to improve data availability and quality and to fine-tune physical-based process models using monitoring data from a wide range of sites. In turn, this will enable cost-effective, targeted and proactive interventions by asset managers to deliver a resilient network.

\section{Conclusion}

This paper describes the physical-based process model architecture of the Futurenet approach to infrastructure network resilience modelling in the $2050 \mathrm{~s}$. It provides an outline of the requirements to achieve a quantifiable approach to address changes in the physical condition (capacity) of components of the network at a range of scales (from sub-metre accuracy of individual processes to a network-wide resilience index). Although the remit of the Futurenet project specifically involved the analysis of conditions in 2050, the architecture that has been developed provides a generic modelling concept where any past or future WESQs can be used to drive physical-based process models. Thus, the concept can be used to analyse past performance using historical WESQs as inputs, enabling development, fine-tuning, calibration and 'validation' of the underling physical-based process models. The framework can also be used to investigate the consequences of short-term weather forecasts on asset condition, enabling the establishment of more robust early warning systems. In addition, it can be used to evaluate the possible consequences of network resilience into the future using the 2050 UKCP09 downscaled weather forecasts, combined with forecasted user changes.

The present understanding of both physical process performance and future demand scenarios is still incomplete and carries large uncertainties. There is a need to continue developing the physical-based models that drive transport infrastructure condition assessments, and this requires the following.

- More detailed and better accessible datasets. Most datasets are currently affected by incomplete and missing data, limiting their usefulness for corridor-wide physical process modelling. It has become apparent that data across several agencies have become fragmented over time and this has highlighted a need for a transparent approach to asset data management and data accessibility to enable more detailed analysis of transport infrastructure asset conditions.

- Further investigation of climate forecasts (e.g. Kay and Jones, 2012) looking at higher resolution, spatial coherence and downscaling extremes.

- Improvements in modelling capability, including modelling platforms capable of managing large volumes of data 
Transport

Volume 167 Issue TR5
Forecasting infrastructure resilience to

climate change

Dijkstra, Dixon, Crosby et al. generated by sophisticated, high-resolution physical-based models (e.g. Booth et al., 2013; Clarke et al., 2006; Davies et al., 2008; Rouainia et al., 2009; Smethurst et al., 2006, 2012).

- The development of detailed deterministic, physical-based models capable of dealing with dynamic equilibria and threshold exceedance.

- Further analyses of complex feedbacks and interactions between physical processes and user behaviour.

The Futurenet project approach to modelling physical processes impacting on the condition of infrastructural elements does not claim to have generated a complete suite of physical-based models to enable such an analysis at this stage. It should be recognised that this is an evolutionary process to produce a system that can be used reliably to provide process-response models at resolutions capable of forecasting infrastructure asset condition changes that will significantly influence management practices and the performance of the asset.

\section{Acknowledgements}

The authors are grateful to the Highways Agency and Network Rail for use of their data and to the EPSRC-funded (EP/ G060770/1) Futurenet team for their continuing support. Tom Dijkstra and David Gunn publish with the permission of the Executive Director of BGS (NERC).

\section{REFERENCES}

Berkhout F, Hertin J and Jordan A (2002) Socio-economic futures in climate change impact assessment: using scenarios as 'learning machines'. Global Environmental Change 12(2): $83-95$.

Booth AJ, El-Hamalawi A and Dixon N (2013) Modelling suctions in a cutting with a bimodal soil water characteristic curve and hydraulic conductivity function. In Proceedings of GeoCongress 2013: Stability and Performance of Slopes and Embankments (Meehan L, Pradel D, Pando MA and Labuz JF (eds)). ASCE, Reston, VA, USA, Geotechnical special publication 231, pp. 402-412.

Bouch C, Jaroszweski D, Baker C et al. (2011) Future resilient transport networks (Futurenet): an overview of the Futurenet project with particular reference to railway aspects. Proceedings of 9th World Congress on Railway Research, Lille, France. See http://p.sparkrail.org (accessed 26/04/2013).

Bouch C, Ryley T, Baker C et al. (2012) Future resilient transport networks (Futurenet): assessing transport network security in the face of climate change. Proceedings of Transportation Research Board 91st Annual Meeting. TRB, Washinton DC, USA. See http://amonline.trb.org (accessed 26/04/2013); Paper No. 12-0279.

Cabinet Office (2011) Keeping the Country Running: Natural Hazards and Infrastructure. Civil Contingencies Secretariat, Cabinet Office, London, UK.
Chapman L (2007) Transport and climate change: a review. Journal of Transport Geography 15(5): 354-367.

Christierson BV, Vidal JP and Wade SD (2012) Using UKCP09 probabilistic climate information for UK water resource planning. Journal of Hydrology 424-425: 48-67.

CILT UK (Chartered Institute of Logistics and Transport in the UK) (2011) Vision 2035 - A Report on the Future of Logistics and Transport in the UK. CILT UK, Corby, UK.

Clarke GRT, Hughes DAB, Barbour SL and Sivakumar V (2006) The implications of predicted climate changes on the stability of highway geotechnical infrastructure: a case study of field monitoring of pore water response. Proceedings of EIC Climate Change Technology 2006, Ottawa, Canada. See http://ieexplore.ieee.org (accessed 26/04/2013).

Curry A, Hodgson T, Kelner R and Wilson A (2006) Intelligent Infrastructure Futures. The Scenarios - Towards 2055. Department of Trade and Industry, London, UK, Publication 8155.

Davies O, Rouainia M, Glendinning S and Birkinshaw SJ (2008) Predicting seasonal shrink swell cycles within a clay cutting. In Advances in Transportation Geotechnics (Ellis E, Yu HS, McDowell G, Dason A and Thom N (eds)). Taylor \& Francis, London, UK, pp. 481-486.

Defra (Department for Environment, Food and Rural Affairs) (2011) Climate Resilient Infrastructure: Preparing for a Changing Climate. Defra, London, UK.

Dijkstra TA and Dixon N (2010) Climate change and slope stability: challenges and approaches. Quarterly Journal of Engineering Geology and Hydrogeology 43(4): 371-385.

Glendinning S, Hall J and Manning L (2009) Asset management strategies for infrastructure embankments. Proceedings of the Institution of Civil Engineers - Engineering Sustainability 162(2): 111-120.

Goulden M and Dingwall R (2012) Managing the future: models controls and the management of uncertainty. In Transport and Sustainability, Volume 2: Transport and Climate Change (Ryley T and Chapman L (eds)). Emerald Group Publishing, Bingley, UK, pp. 9-38.

HM Treasury (2011) National Infrastructure Plan. HM Treasury, London, UK.

Hooper E and Chapman L (2012) The impacts of climate change on national road and rail networks. In Transport and Sustainability, Volume 2: Transport and Climate Change (Ryley T and Chapman L (eds)). Emerald Group Publishing, Bingley, UK, pp. 105-136.

ICE (Institution of Civil Engineers) (2010) State of the NationInfrastructure 2010. ICE, London, UK.

IPCC (Intergovernmental Panel on Climate Change) (2007) Climate Change 2007: the Physical Science Basis. Contribution of Working Group I to the Fourth Assessment Report of the Intergovernmental Panel on Climate Change (Solomon S, Qin D, Manning M et al. (eds)). Cambridge University Press, Cambridge, UK.

Jaroszweski D, Chapman L and Petts J (2010) Assessing the potential impact of climate change on transportation: the 
need for an interdisciplinary approach. Journal of Transport Geography 18(2): 331-335.

Jenkins GJ, Perry MC and Prior MJO (2009) The Climate of the United Kingdom and Recent Trends. Met Office Hadley Centre, Exeter, UK.

Jones PD, Kilsby CG, Harpham C, Glenis V and Burton A (2009) UK Climate Projections Science Report: Projections of Future Daily Climate for the UK from the Weather Generator. University of Newcastle, Newcastle upon Tyne, UK.

Kay AL and Jones RG (2012) Comparison of the use of alternative UKCP09 products for modelling the impacts of climate change on flood frequency. Climatic Change 114(2): 211-230.

Koetse MJ and Rietveld P (2009) The impact of climate change and weather on transport: An overview of empirical findings. Transportation Research Part D 14(3): 205-221.

Loveridge FA, Spink TW, O'Brien AS, Briggs KM and Butcher D (2010) The impact of climate and climate change on infrastructure slopes, with particular reference to southern England. Quarterly Journal of Engineering Geology and Hydrogeology 43(4): 461-472.

Murphy JM, Sexton D, Jenkins G et al. (2009) UKCP09 Climate Change Projections Science Report. Met Office Hadley Centre, Exeter, UK.

O'Brien AS (2007) Rehabilitation of urban railway embankments - investigation, analysis and stabilisation. In Proceedings of the 14th European Conference on Soil Mechanics and Geotechnical Engineering (Cuéllar V, Dapena A, Alonso E et al. (eds)). MillPress, Madrid, Spain, vol. 1, pp. 125-143.

Perry J, Pedley M and Reid M (2001) Infrastructure Embankments - Condition Appraisal and Remedial Treatment. Construction Industry Research and Information Association, London, UK, Report C550.

Perry J, Pedley M and Reid M (2003) Infrastructure Embankments - Condition Appraisal and Remedial Treatment. Construction Industry Research and Information Association, London, UK, Report C592.

Quinn AD and Baker CJ (2010) Spatial and temporal correlations of wind speeds. Proceedings of the Institution of Civil Engineers - Structures and Buildings 163(2): 65-72.

RAIB (Rail Accident Investigations Branch) (2008) Network Rail's Management of Existing Earthworks. Department for Transport, London, UK.

Roca M and Whitehouse R (2012) Scour risk assessment at river crossings. Proceedings of ICSE6, Paris, France, HRPP528. See http://scour-and-erosion.baw.de/icse6-cd/data/articles/ 000305.pdf (accessed 13/08/2014).

Rogers CD, Bouch CJ, Williams S et al. (2012) Resistance and resilience-paradigms for critical local infrastructure. Proceedings of the Institution of Civil Engineers - Municipal Engineer 165(2): 73-83.

Rouainia M, Davies O, O'Brien T and Glendinning S (2009) Numerical modelling of climate effects on slope stability. Proceedings of the Institution of Civil Engineers Engineering Sustainability 162(2): 81-89.

Rowlands DJ, Frame DJ, Ackerley D et al. (2012) Broad range of
2050 warming from an observationally constrained large climate model ensemble. Nature Geoscience 5(4): 256-260.

RSSB (Rail Safety and Standards Board) (2004) Railway Safety Implications of Weather, Climate and Climate Change: Final Report. RSSB, London, UK, AEAT/RAIR/76148/R03/005.

RSSB (2005) Safe Management of Railways Structures (Phase 2). Objective 2 - Vegetation and its Effect on Slope Stability. RSSB, London, UK.

Ryley T and Chapman L (2012) Transport and Sustainability, Volume 2: Transport and Climate Change. Emerald Group Publishing, Bingley, UK.

Smethurst JA, Clarke D and Powrie W (2006) Seasonal changes in pore water pressure in a grass-covered cut slope in London Clay. Géotechnique 56(8): 523-538.

Smethurst JA, Clarke D and Powrie W (2012) Factors controlling the seasonal variation in soil water content and pore water pressures within a lightly vegetated clay slope. Géotechnique 62(5): 429-446.

Stern NH (2007) The Economics of Climate Change: The Stern Review. Cambridge University Press, Cambridge, UK.

Take WA and Bolton MD (2004) Identification of seasonal slope behaviour mechanisms from centrifuge case studies. In Advances in Geotechnical Engineering: The Skempton Conference (Jardine RJ, Potts DM and Higgins KG (eds)). Thomas Telford, London, UK, pp. 992-1004.

Thornton H, McCarthy R, Liggins F et al. (2010) The Impact of Climate Change on the GB Rail Network: Phase 2 Findings. Met Office Hadley Centre on behalf of Network Rail, Exeter, UK.

URS (URS Corporation Ltd) (2010) Adapting Energy, Transport and Water Infrastructure to the Long-term Impacts of Climate Change. URS, San Francisco, CA, USA, Report RMP/5456.

Wilks JH, Dijkstra TA and Dixon N (2012) Forecasting transport infrastructure slope failures in a changing climate. In Landslides and Engineered Slopes: Protecting Society through Improved Understanding. Proceedings of the 11th International and 2nd North American Symposium on Landslides and Engineered Slopes, Banff, Canada (Eberhardt E, Froese C, Turner AK and Leroueil S (eds)). CRC Press/ Balkema, Leiden, the Netherlands, vol. 1, pp. 386-393.

\section{WHAT DO YOU THINK?}

To discuss this paper, please email up to 500 words to the editor at journals@ice.org.uk. Your contribution will be forwarded to the author(s) for a reply and, if considered appropriate by the editorial panel, will be published as a discussion in a future issue of the journal.

Proceedings journals rely entirely on contributions sent in by civil engineering professionals, academics and students. Papers should be 2000-5000 words long (briefing papers should be 1000-2000 words long), with adequate illustrations and references. You can submit your paper online via www.icevirtuallibrary.com/content/journals, where you will also find detailed author guidelines. 